\title{
Analysis of the Impact of the Change of Primary and Secondary AISi9Cu3 Alloy Ratio in the Batch on its Performance
}

Dana Bolibruchová, Marek Matejka, Michal Kuriš

University of Zilina, Faculty of Mechanical Engineering, University of Zilina, Zilina. Slovak Republic. E-mail: danka.bolibruchova@fstroj.uniza.sk,marek.matejka@fstroj.uniza.sk,michal.kuris@fstroj.uniza.sk

The ratio of primary and secondary alloy in the batch is important in determining and evaluating the quality of the alloy. The resulting quality of the casting and the costs associated with its production are directly related to the composition of the raw materials entering the smelting process. With the use of an alloy composed of a high proportion of recycled material a negative effect on performance can be expected despite its economic benefits. Based on the results of thermal analysis, mechanical properties and microstructure analysis, the effect of changing the primary and secondary AISi9Cu3 alloy ratio in the batch was determined. A negative effect of the increasing proportion of secondary alloy was already evident in the case of an alloy composed of a 50-50\% ratio. Conversely, in the case of artificial aging, a positive effect was observed with increasing amounts of secondary alloy.

Keywords: AlSi secondary alloy, Mechanical properties, Metallography, Fe phase

\section{Introduction}

Recycling is a major aspect in continuing the lifecycle of aluminum and its alloys. Almost $100 \%$ of the waste from the production of aluminum products is currently recycled. A significant part (about 70\%) of recycled aluminum is used in the production of aluminum alloys cast mainly for the automotive industry. Secondary aluminum metallurgy, as well as many other recycling processes, is an important economic and environmental issue. The recycling process enables the economy of raw materials and energy savings. For this reason, foundries today use an increasingly large amount of remelted material in the batch, which may account for several tens of percent of the total batch. However, the recycling process through remelting may cause some change in the melt quality. In particular, it is possible to achieve changes in the chemical composition. In the case of elements with a higher affinity for oxygen, overburns can occur and thus reduce their content in the alloy. Possible diffusion of environmental elements, in particular of unprotected steel, tools and a crucible, is also associated with remelting [1].

The solidification of Al-Si-Cu-type alloys is characterized by the formation of three basic structural components. $\alpha$-phase particles are formed at liquid-state temperatures, followed by the formation of the Al-Si eutectics, and copper-enriched eutectic phases are formed in the final phase. In the case of secondary alloys, it is possible to analyze, on the solidification curve, intermetallic phases rich in another element introduced there in the form of impurities, for example. The most common impurity element is iron. The presence of iron consequently affects most of the properties important for the overall casting quality. The increased presence of iron is associated with the formation of intermetallic phases which negatively affect the resulting properties of the alloy by their inappropriate morphology $[2,3]$.

In their work, Seifeddine, Samuel, and Taylor in particular, report that a negative effect begins to appear at low iron levels, accompanied by a decrease in tensile strength and ductility. A significant reduction in these properties occurs when the critical iron content is exceeded. The critical iron content is directly proportional to the concentration of silicon in the alloy. By increasing the silicon content in the alloy, the permissible amount of iron is increased before the start of the $\beta$-phase formation, when the Al-Si eutectic begins to form. According to Taylor, the negative effect of iron on ductility is due to two reasons. Decrease in ductility occurs with increasing iron content, thus increasing the number and size of iron-based intermetallic phases directly involved in the fracture mechanism. As a second reason, Taylor says that increasing the iron content results in an increase in porosity with a consequent decrease in ductility. Taylor explains the porosity formation process by virtue of the fact that Al-Si eutectic seed formation on $\mathrm{Al}_{5} \mathrm{FeSi}$ phase plates causes a rapid stop of the permeability resulting in a complete stop of the melt flow front. Critical Fe content in wt. \% can also be calculated from relation [3-7]:

$$
\boldsymbol{F} e_{\text {crit }} \approx 0.075 x(\% S i)-0.05
$$

Copper in this set-up lowers the liquid temperature, worsens its ductility, and improves its machinability and thermal conductivity. The biggest disadvantage is the reduced corrosion resistance. The presence of copper as an additive element allows the application of heat treatment by precipitation hardening. It is a diffusion process, which takes place in the casting structure after solution annealing, in which the solid solution is depleted of the additive elements. During precipitation from the supersaturated solid solution, the mechanical and physical properties of the casting change due to the formation of lattice deformations and internal stresses. The induced stresses are the cause of the increasing strength and hardness of the alloy $[1,8]$.

\section{Materials and experiments procedure}

In order to evaluate the impact of the ratio of primary and secondary alloy in the batch, a sub-eutectic AlSi9Cu3 alloy was chosen as an experimental material. The secondary alloy for the experiment was made by remelting the casting waste, namely the remnants of ingots, inlet and inflow systems. The chemical composition of the primary and secondary alloys is shown in Tab. 1. In another part of the experiment, five alloys designated $20-80,50-50$, 
$70-30,80-20$, and $90-10$ were cast one after another. In the above sequence, the first number indicates the percentage of the secondary alloy in the batch, and the second number shows the primary alloy ration in the batch. The chemical composition of the alloys is shown in Tab. 1. Casting was carried out in an electric resistance furnace at a casting temperature of $750 \pm 5^{\circ} \mathrm{C}$. Ten samples were cast from each melt to test the mechanical properties. These were cast into a metal mold at a temperature of 150 $\pm 5{ }^{\circ} \mathrm{C}$. Alloys analysis was performed on samples after natural aging (about $160 \mathrm{~h}$ at $23^{\circ} \mathrm{C}$ ) and on samples after heat treatment $\left(\mathrm{T} 5\right.$ - artificial aging at $200 \pm 5^{\circ} \mathrm{C}$ for 4 hours and cooling in water). We did not degas the alloy.

Tab. 1 Chemical composition of the primary, secondary and experimentals AlSi9Cu3 alloys

\begin{tabular}{|c|c|c|c|c|c|c|c|c|c|}
\hline $\begin{array}{c}\text { Elements } \\
{[\text { wt. \%] }}\end{array}$ & $\mathbf{S i}$ & $\mathbf{F e}$ & $\mathbf{C u}$ & $\mathbf{M n}$ & $\mathbf{M g}$ & $\mathbf{N i}$ & $\mathbf{Z n}$ & $\mathbf{T i}$ & $\mathbf{C r}$ \\
\hline Primary & $\mathbf{9 . 5 5 9}$ & $\mathbf{0 . 1 7 6}$ & $\mathbf{0 . 1 8 6}$ & $\mathbf{0 . 2 2 1}$ & $\mathbf{0 . 1 8 1}$ & $\mathbf{0 . 1 9 6}$ & $\mathbf{0 . 1 8 7}$ & $\mathbf{0 . 0 3 8}$ & $\mathbf{0 . 0 2 7}$ \\
\hline Secondary & $\mathbf{9 . 2 9 4}$ & $\mathbf{1 . 6 7 4}$ & $\mathbf{2 . 0 7 4}$ & $\mathbf{0 . 1 8 4}$ & $\mathbf{0 . 3 4 8}$ & $\mathbf{0 . 1 2 9}$ & $\mathbf{1 . 0 1 6}$ & $\mathbf{0 . 0 3 4}$ & $\mathbf{0 . 1 1 3}$ \\
\hline $\mathbf{2 0}-\mathbf{8 0}$ & 9.507 & 1.294 & 2.197 & 0.231 & 0.391 & 0.122 & 1.044 & 0.035 & 0.49 \\
\hline $\mathbf{5 0}-\mathbf{5 0}$ & 9.418 & 1.419 & 2.173 & 0.223 & 0.361 & 0.134 & 1.041 & 0.033 & 0.042 \\
\hline $\mathbf{7 0}-\mathbf{3 0}$ & 9.245 & 1.619 & 1.92 & 0.209 & 0.344 & 0.108 & 0.961 & 0.031 & 0.112 \\
\hline $\mathbf{8 0}-\mathbf{2 0}$ & 9.415 & 1.627 & 1.98 & 0.206 & 0.358 & 0.156 & 1.07 & 0.032 & 0.101 \\
\hline $\mathbf{9 0}-\mathbf{1 0}$ & 9.291 & 1.643 & 2.143 & 0.199 & 0.357 & 0.127 & 1.046 & 0.032 & 0.106 \\
\hline
\end{tabular}

\section{Results}

\subsection{Thermal and microstructure analysis}

The process of crystallization of alloys with different ratios was evaluated by thermal analysis. During measurement, a K-type (NiCr-Ni) thermocouple was used in the center of a cylindrical metal mold with a diameter of $34 \mathrm{~mm}$ and a height of $50 \mathrm{~mm}$. Values were recorded in the LabView $2 \mathrm{~Hz}$ software. Cooling curves and their first derivatives were generated from the measured values saved in Excel program to accurately determine the characteristic crystallization temperature of the individual

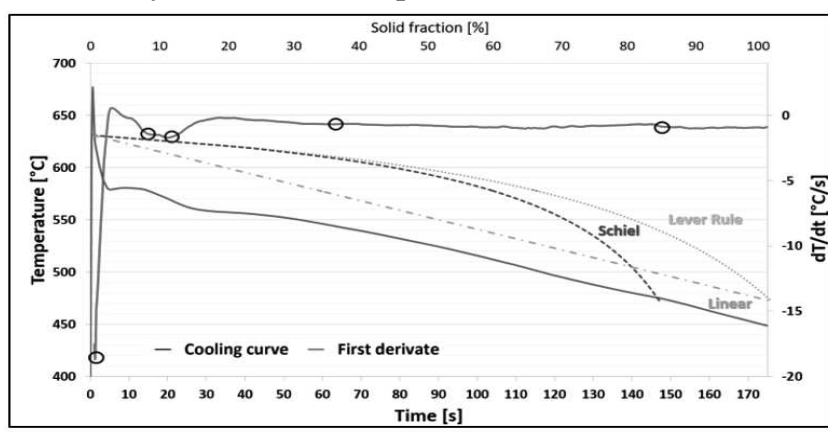

a) $20-80$ alloy structural components of the alloy under investigation Fig. 1 shows a comparison of the cooling curves and their first derivatives of the alloy with the lowest secondary alloy ratio of $20-80$ and the alloy with the highest secondary alloy proportion in the batch $-90-10$. Together with the curves and their derivatives, Fig. 1 shows the comparison of curves characterizing the proportion of solid and liquid phases depending on temperature. These curves were obtained on the basis of the linear and Scheil equations and the Lever rule [9].

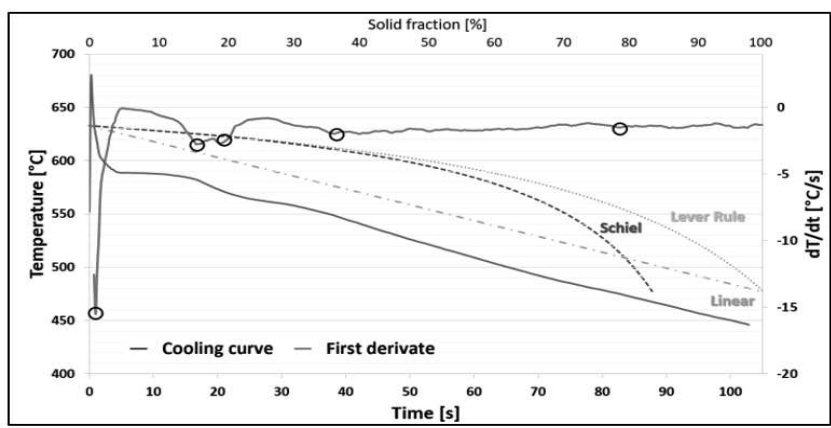

b) $90-10$ alloy

Fig. 1 Cooling curve and its first derivate of experimental alloys

Increasing the proportion of secondary alloy did not manifest any significant effect on the individual crystallization temperatures of the structural components. Iron-based intermetallic phases are an exception. The gradual increase in the proportion of secondary alloy in the batch caused a linear increase in $\mathrm{Fe}$ wt. \% in the alloys, and thus a gradual increase in nucleation temperatures of these phases. The nucleation temperatures of the ferrous phases were at the level of $\mathrm{T}_{\mathrm{AISiFe}}=574{ }^{\circ} \mathrm{C}$ for the alloy with the lowest proportion of secondary alloy $(20-80)$, for the alloy with a $50-50$ equilibrium ratio the temperature was $\mathrm{T}_{\mathrm{AlSiFe}}=577^{\circ} \mathrm{C}$, and for the alloy with the highest proportion of secondary alloy $(90-10)$ it was $\mathrm{T}_{\mathrm{AlSiFe}}=584{ }^{\circ} \mathrm{C}$. Tab. 2. gives characteristic phase conversion temperatures for all structural components.

Tab. 2 Temperature of characteristic reaction of experimental alloys

\begin{tabular}{|c|c|c|c|c|c|}
\hline Alloy & $\mathbf{T}_{\mathbf{L i q}}\left[{ }^{\circ} \mathbf{C}\right]$ & $\mathbf{T}_{\text {AlFeSi }}\left[{ }^{\circ} \mathbf{C}\right]$ & $\mathbf{T}_{\text {AISi }}\left[{ }^{\circ} \mathbf{C}\right]$ & $\mathbf{T}_{\text {AISiCu }}\left[{ }^{\circ} \mathbf{C}\right]$ & $\mathbf{T}_{\text {Sol }}\left[{ }^{\circ} \mathbf{C}\right]$ \\
\hline $\mathbf{2 0}-\mathbf{8 0}$ & 630 & 574 & 571 & 542 & 474 \\
\hline $\mathbf{5 0}-\mathbf{5 0}$ & 631 & 577 & 569 & 541 & 477 \\
\hline $\mathbf{7 0}-\mathbf{3 0}$ & 633 & 579 & 572 & 542 & 476 \\
\hline $\mathbf{8 0}-\mathbf{2 0}$ & 628 & 581 & 569 & 545 & 473 \\
\hline $\mathbf{9 0}-\mathbf{1 0}$ & 632 & 584 & 570 & 543 & 476 \\
\hline
\end{tabular}


The microstructure of the alloy with $80 \%$ primary alloy $(20-80)$ consists of an $\alpha$-phase matrix, eutectic silicon excreted in the so-called unmodified shape, and the iron-based intermetallic phases excreted in the needlelike morphology uniformly distributed in the clay matrix (Fig. 2a). With a balanced ratio of primary and secondary alloys in the batch, the microstructure of the alloy $(50-$ 50) did not change, only a slight increase in the length of

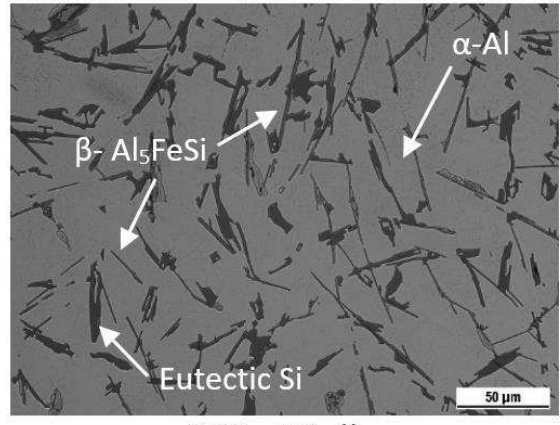

a) $20-80$ alloy

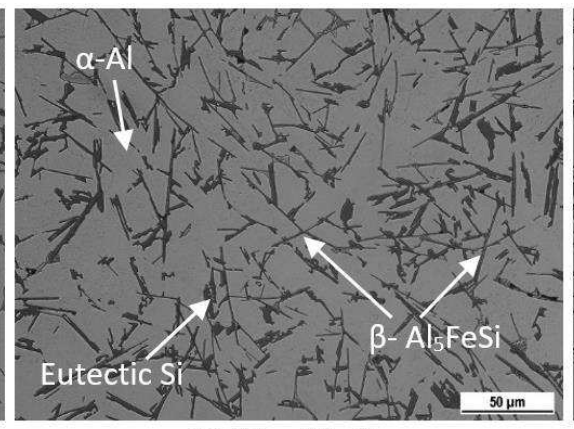

b) 50 - 50 alloy the iron needle-like formations can be observed (Fig. 2b). For alloys consisting of a larger proportion of secondary alloy (alloy $70-30$ and alloy $90-10$ ), the microstructure is characterized by a large number of long and thin needle-like formations of the iron-rich phases (Fig. 2c). Increasing the proportion of secondary material also resulted in local thickening of the eutectic silicon grains (Fig. 2c).

Fig. 2 Microstructure of AlSi9Cu3 alloy with different ratio of primary and seconday alloys

For more detailed analysis, we performed measurements of average needle lengths of ferric $\beta$ $\mathrm{Al}_{5} \mathrm{FeSi}$ needles. The average length measurements were taken on microstructure images at 500-times magnification. The measurement confirmed the expected increase in needle lengths with a gradual increase in the proportion of secondary alloy (Fig. 3b). The average needle length for the $20-80$ alloy was $33.4 \mu \mathrm{m}$, and that for the alloy with an equalized ratio $(50-50)$ was 38.6 $\mu \mathrm{m}$. The highest value of $50.9 \mu \mathrm{m}$ was measured for the alloy with $90 \%$ secondary alloy $(90-10)$, which represents an increase by approximately $35 \%$.

The $\mathrm{Fc}_{\text {rit }}$ value was exceeded in all alloys by a gradual

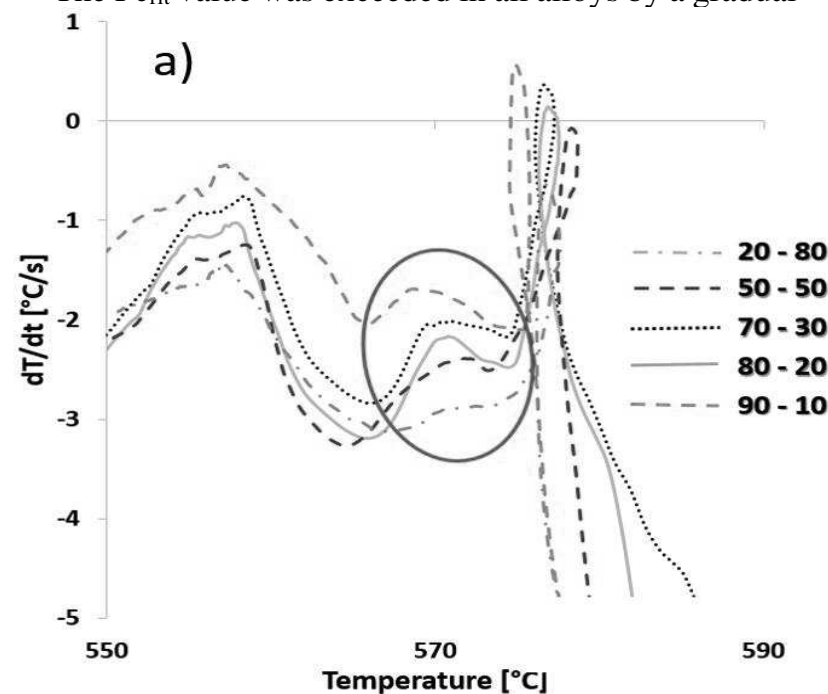

increase in wt. $\% \mathrm{Fe}$. The $\mathrm{Fc}_{\text {rit }}$ value (1) indicates that the iron-rich phases will be excluded well before the eutectic silicon phases [3]. The ferric intermetallic phases formed before the crystallization of the AlSi eutectic tend to form phases of much larger dimensions than those formed after the eutectic solidifies. The detailed thermal analysis of the ferric phase nucleation region (Fig. 3a) confirms that the iron-rich phases were preferably excluded before the AlSi eutectic. It can also be seen from the detailed image that with a gradual increase in $\mathrm{Fe}$ wt. \% results in increased latent heat released by the crystalline conversion of these phases, which may be directly related to the increase in the average lengths of the ferric phases.

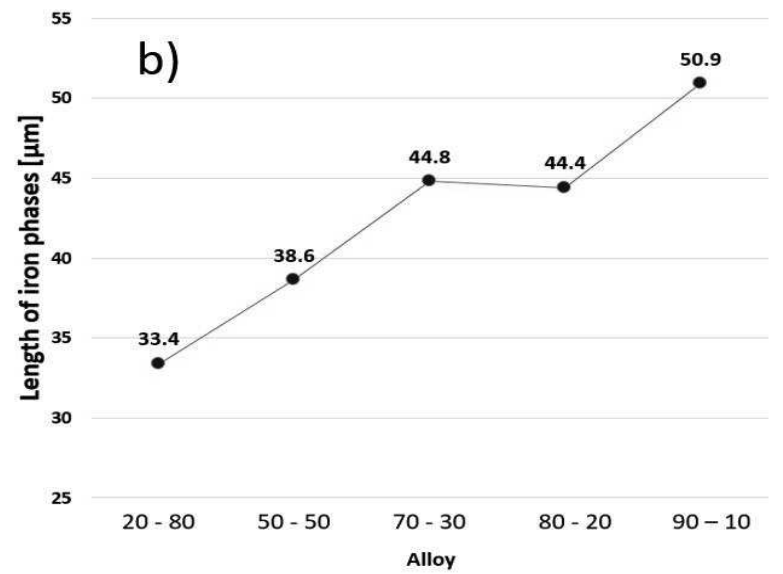

Fig. 3 a) Iron reach phases detected using first derivative curves of AlSi9Cu3 alloys with various ratio of primary and seconadry alloy $b$ ) Relationship between length of iron phases and alloy with various ratio of primary and seconadry alloy

\subsection{Application of Artificially aged (T5)}

The effect of artificial aging manifested as minimal in the microstructure images at 500-time magnification (Fig. 4). In comparison with the alloy without artificial aging, partial spheroidization - grain refinement of eutectics can be observed. By measuring the average lengths of the needles of the ferric phases we found out that the application of artificial aging had a positive effect on their length. The graph shown in Fig. 5 shows a reduction in the average needle lengths of the ferric phase needles for all alloys. It 
can also be seen from the graph that the efficiency of artificial aging increased with the increasing proportion of secondary alloy in the batch, and/or with increasing average length of needles of iron-rich phases. In the $20-$ 80 alloy, artificial aging resulted in a shortening of the needle length by $1.3 \mu \mathrm{m}$ on average compared to natural aging. In the case of the alloy with a $90 \%$ secondary alloy proportion, the shortening due to artificial aging was 6 $\mu \mathrm{m}$ on average.

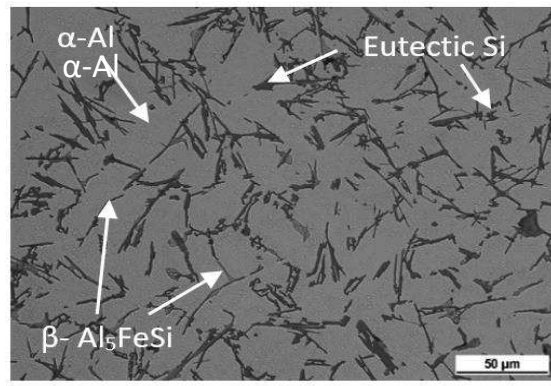

a) $20-80$ alloy

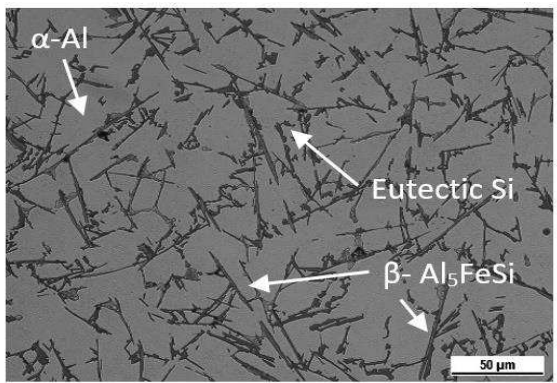

b) $50-50$ alloy

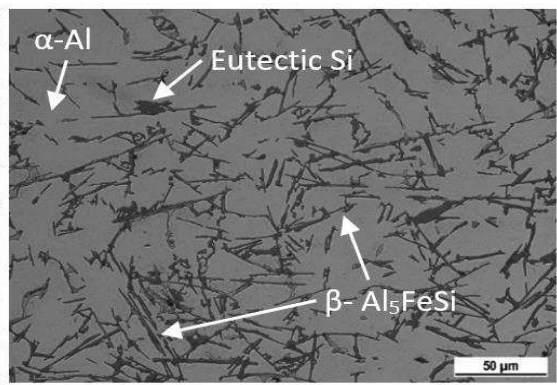

c) $90-10$ alloy

Fig. 4 Microstructure of AlSi9Cu3 alloy with different ratio of primary and seconday alloys after artificaly aged

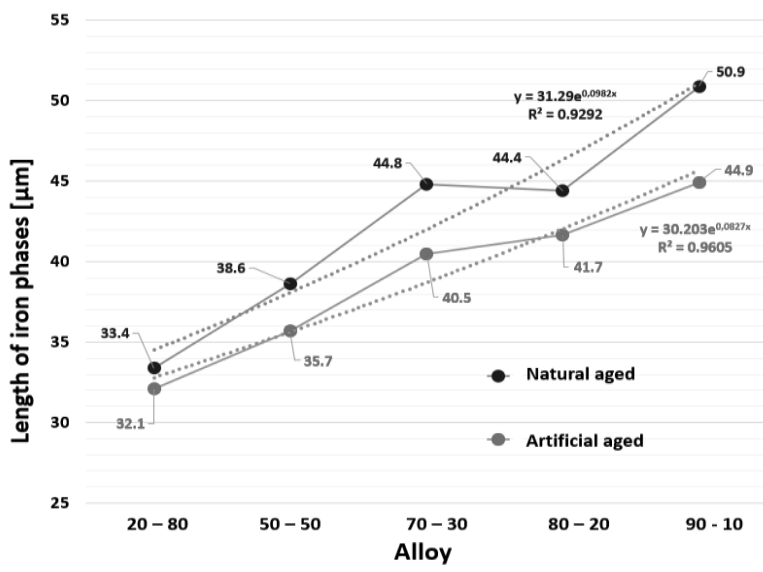

Fig. 5 Relationship between length of iron phases and alloy with various ratio of primary and seconadry alloy and alloy stade

\subsection{Porosity and density index}

The change in alloy quality due to different ratios of primary and secondary alloys in the batch and increasing iron content was also evaluated in terms of the melt porosity and gasification. A double weighing method was used to determine the change in gassing due to remelting. From the results shown in the graph (Fig. 6a) it can be concluded that the change in the ratio was not critical to the melt gassing value. The $20-80$ alloy exhibits gassing, or the density index, of $5.88 \%$ - where with an increase in the secondary alloy ratio to $70 \%$ resulting in a density index falling to a minimum of $4.07 \%$, and there was a sharp increase in values with a further increase in the secondary alloy ratios to $80 \%$ and $90 \%$, respectively. The highest value of $10.37 \%$ was measured for the $90-10$ alloy. Samples solidified under vacuum served to evaluate the bi-film index, which determines the overall length of the resulting pores. The bi-film index is calculated using the relation:

$$
\text { Biflm Index }=\sum \text { (Pore length) }
$$

The lengths of the individual pores were measured on cross-sections of the samples (Fig. 6c). The graph displayed in Fig. 6b shows the total pore length (2) (major axis - blue color) and the average pore length (minor axis red color). The course of the values is identical to the gassing index.

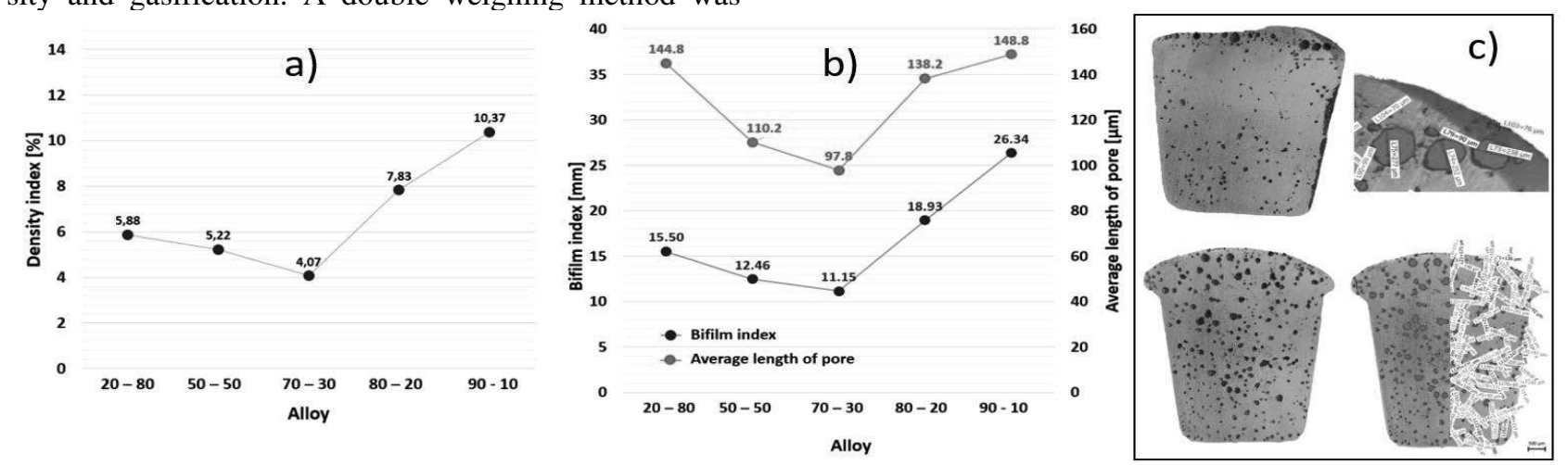

Fig. 6 a) Relationship between density index and alloy b) Relationship between bifilm index and alloy c) Pieces from a test of density index and method of measurement od pure length of pore

The evaluation of surface porosity was performed on samples obtained from the test rods for mechanical testing in the condition after natural and artificial aging (Fig. 7a). Surface porosity of the samples after natural aging was not significantly affected by the ratio change.
The highest value was measured for the alloy with the highest proportion of secondary alloy. By application of artificial aging, there was a visible increase in surface porosity values, especially in alloys with a higher proportion of secondary alloy $(70-30,80-20,90-10)$. 
Exposing the samples to $200^{\circ} \mathrm{C}$ for 4 hours resulted in up to three-fold increase in surface porosity in some cases.

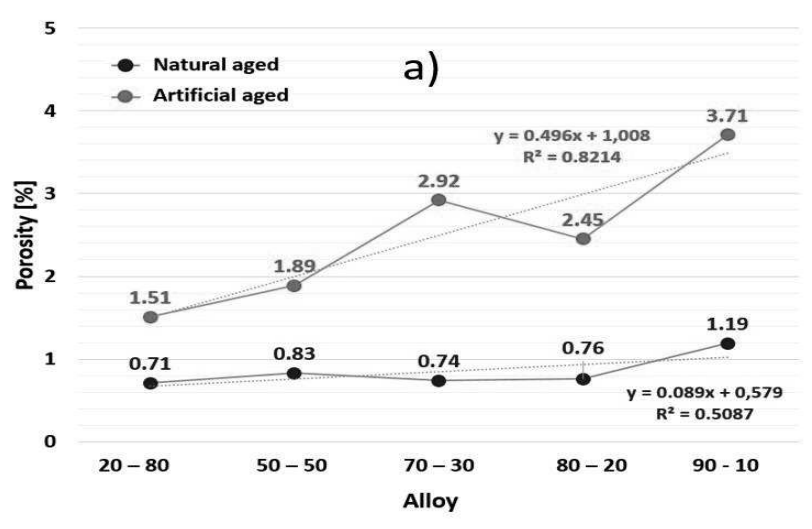

Figs $7 b, c, d$, e show the increase in surface porosity of 20 -80 and $90-10$ alloys due to artificial aging.

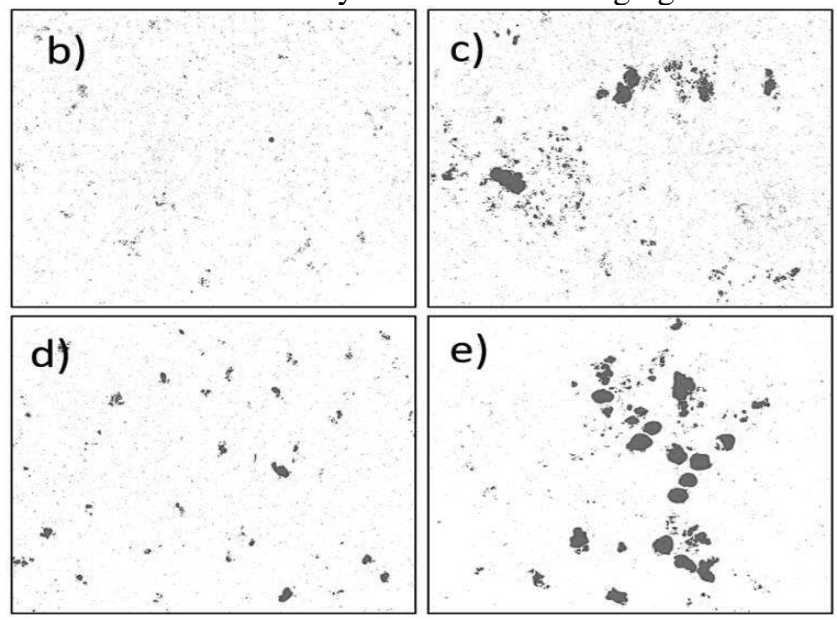

Fig. 7 a) Relationship between porosity and alloy; measurements porosity of AlSi9Cu3 alloy b) 20 - 80 after natural aging c) 20 - 80 after artificaly aged d) 90 - 10 after natural aging e) 90-10 after artificaly aged

\subsection{Mechanical properties}

The tensile strength and the the corresponding yield strength, as can be seen in the graphs shown in Fig. 8, reached the expected course. Best values were obtained with an alloy with $80 \%$ primary alloy proportion, $\mathrm{R}_{\mathrm{m}}=$ $174 \mathrm{MPa}$ and $\mathrm{Rp}_{0.2}=97 \mathrm{MPa}$. The observed characteristics (properties) gradually decreased when we increased the proportion of secondary alloy up to $70 \%$. There was a stabilized period from the $70-30$ to $90-10$ alloy, and the values were at approximately the same levels. The degradation of tensile strength and the the corresponding yield strength can be attributed to the increasing presence

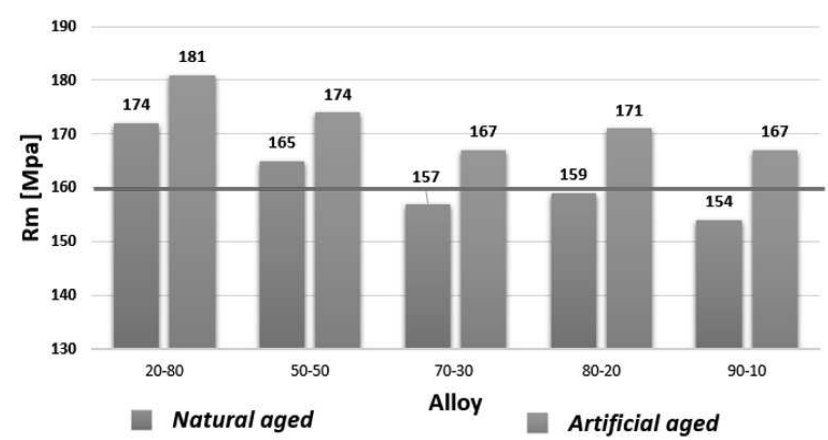

a) and increased lengths of ferric phases $\left(\beta-\mathrm{Al}_{5} \mathrm{FeSi}\right)$ in unfavorable needle morphology in the structure of alloys with a higher proportion of secondary alloy, thereby disrupting the structure. The shape of the ferric compound has a greater effect than its amount in the alloy. Sharp endings of the needle-like phases act as stress concentrators and local formations of micro-cracks and cracks. The application of artificial aging (T5) (orange in the graph) resulted in an increase in the tensile strength and the the corresponding yield strength at all alloy ratios. The red line in the graphs indicates the minimum values required by the standard (EN 17 06) for the gravity cast AlSi9Cu3 alloy.

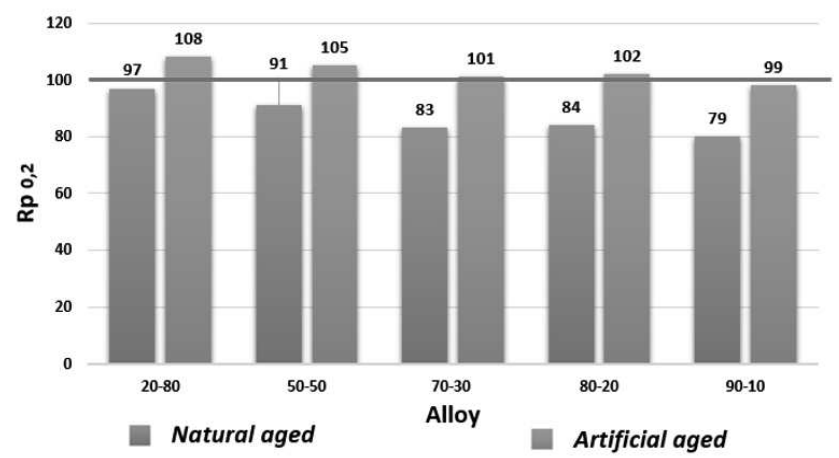

b)

Fig. 8 a) Tensile strength and $(b)$ yield strength depending on experimental alloy and the state the alloy

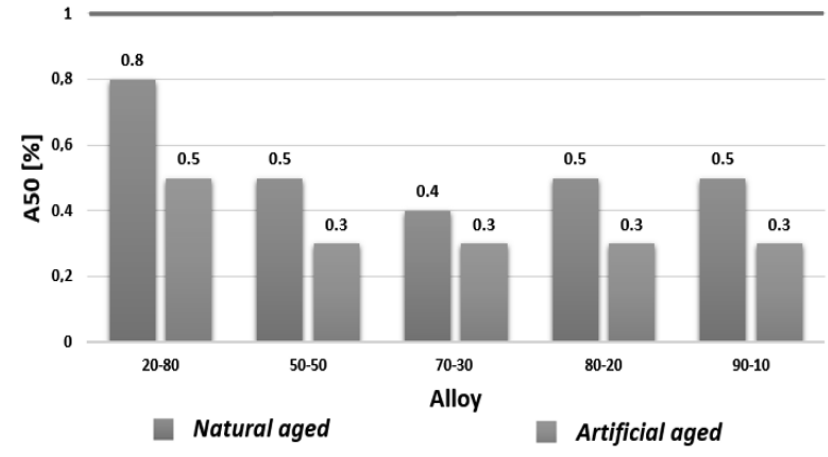

a)

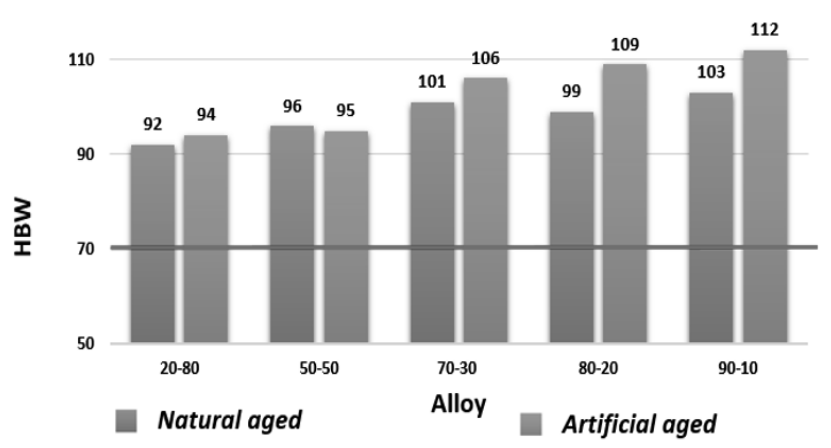

b)

Fig. 9 a) Ductility and (b) Brinell hardness depending on experimental alloy and the state the alloy 
A similar decreasing course was observed with the evaluated ductility (Fig. 9a). Due to the increasing proportion of secondary material in the batch, the ductility values dropped significantly. After artificial aging, the ductility decreased to a minimum in all cases. The hardness results (Fig. 9a) showed that with increasing amount of ferric phases in the structure the hardness values increase as well. Artificial aging, as expected, increased HBW hardness values [8]. The red line in the graphs indicates the minimum values required by the standard (EN 1706 ) for the gravity cast AlSi9Cu3 alloy.

\section{Conclusion}

The evaluation of the results obtained confirmed the expected decrease in the overall quality of the alloy due to the increasing proportion of the secondary alloy. The increasing proportion of the secondary alloy led to an increase in the Fe content in the alloy, and thus exceeding the critical iron content in each of the experimental alloys. The above resulted in the formation of harmful iron phases before the crystallization of the eutectic. The formation of a large number of ferric phases in needle morphology has already been adversely reflected in the crystallization evaluation by increasing the nucleation temperature and releasing more latent heat, which led to a gradual extension of the iron-needle phase lengths. Increased average lengths and increased total number of ferric phases had a major effect on the degradation of observed mechanical properties except for hardness. When compared with EN 17 06, the required minimum in tensile strength was achieved not only by alloys with a high proportion of secondary alloy $(70-30,80-20,90-10)$ and the minimum yield strength reached by the alloy under investigation after natural aging. The change in the ratio of primary and secondary alloys in the batch did not manifest the expected course of change in the density index, as the lowest value was measured for an alloy with $70 \%$ secondary alloy, which was also confirmed by evaluating the pore lengths. The surface porosity was only minimally affected by the ratio change.

The application of artificial aging had a positive effect on the length of the ferric needles and the local refinement of eutectic silicon, and thus the resulting mechanical properties of the investigated alloys, which in all cases exceeded the minimum value required by the standard when assessing tensile strength and agreed yield strength. On the contrary, it was negatively reflected in the evaluation of area porosity and ductility of alloys with different ratio of primary and secondary alloys.

From the results it can be concluded that the gradual increase in the proportion of secondary alloy in the batch led to a relatively visible negative impact already at a balanced ratio of alloys. Important observation occurred in artificial aging, which directly increased its effectiveness with increasing proportion of secondary alloy in the batch.

\section{Acknowledgement}

This article was created as part of the VEGA grant agency: 1/0494/17. The authors hereby thank the Agency for their support.

\section{References}

[1] BOLIBRUCHOVÁ, D. MATEJKA, M. (2018). Analysis of microstructure changes for AlSi9Cu3 alloy caused by remelting. In Manufacturing Technology. ISSN 1213-2489. Vol 18 (6), pp 883888.

[2] DJURDJEVIC, M. B. ODANOVIC, Z. TALIJAN, N. (2011). Characterization of the Solidification Path of AlSi5Cu (1-4 wt. \%) Alloys Using Cooling Curve Analysis. In J. of Metals, pp 51-57

[3] TAYLOR, J.A. (2012). Iron-containing intermetallic phase in Al-Si based casting alloys. In Procedia Materials Science. 2012. Vol 1, pp. 19-33.

[4] SAMUEL A.M, SAMUEL F.H, DOTY H.W. (1996). Observations on the formation of $b$ Al5FeSi phase in 319 type Al-Si alloys. In J. Mater. Sci. Vol. 31, pp 5529-5539

[5] SEIFEDDINE, S. (2007). The influence of Iron on the microstructure and mechanical properties of cast Al-Si-alloys. In Vikteffektiva lättmetallstukturer. Vol. 24

[6] PODPROCKÁ, R., BOLIBRUCHOVÁ, D. (2017). The influence of manganese on elimination harmful effect of iron with different level of iron in the alloy based on Al-Si-Mg. In: Manufacturing Technology. ISSN 1213-2489. Vol. 17 (5), s. 815-819.

[7] HRUBOVČÁKOVÁ, M., VASKOVÁ, I., CONEV, M., BARTOŠOVÁ, M., FUTÁS̆, P. (2017). 3. Influence the composition of the core mixture to the occurrence of veining on castings of cores produced by cold-box-amine technology. In: Manufacturing Technology. ISSN 1213-2489. Vol. 17 (1), s. 39-44.

[8] Stefano, C., GiUlio, T., AlBerto, F., FRANCO, B. (2015). Influence of Ageing Heat Treatment on Microstructure and Mechanical Properties of a Secondary Rheocast AlSi9Cu3(Fe) Alloy. In Materials Science Forum 828-829, s 212-218

[9] MARCHWICA, P. (2012). Microstructual and Thermal Analysis of Aluminum-Silicon and Magnesium-Aluminum Alloys Subjected to High Cooling Rates. Electronic Theses and Dissertations. 557 